\title{
From health to disease- How consistent is the biologic width?
}

\author{
Ritika Arora ${ }^{1, *}$, R. K. Sharma ${ }^{2}$, Shikha Tewari ${ }^{3}$, S. C. Narula ${ }^{4}$, Himanshu Kapoor ${ }^{5}$ \\ ${ }^{1,5}$ Reader, ${ }^{2,3}$ Professor, ${ }^{4}$ Professor \& HOD, ${ }^{1-4}$ Dept. of Periodontology, ${ }^{5}$ Dept. of Pedodontics and Preventive Dentistry, \\ ${ }^{1,5}$ Subharti Dental College and Hospital, Meerut, Uttar Pradesh, ${ }^{2-4}$ Pt. B.D. Sharma Institute of Dental Sciences, Rohtak, Haryana, \\ India
}

*Corresponding Author:

Email: drritika44@gmail.com

\begin{abstract}
Context: Biologic width (BW) is an important entity to consider when planning restorative or prosthetic procedures. Though many studies are available in the literature that offer varying dimensions for this entity in healthy dentition, there is a paucity of studies that have measured biologic width in cases of periodontitis.

Aims: This study was designed with the aim of measuring BW dimensions in both health and disease.

Settings and Design: 41 systemically healthy patients with an age range of $18-42$ years were included in this analytical study. Material and Methods: BW dimensions were measured by subtracting sulcus depth from the distance between gingival margin and osseous crest by trans sulcular probing. Measurements were again made in 20 patients with advanced periodontitis after completion of phase one therapy.

Statistical analysis: Mean and standard deviation for the groups were calculated and one way analysis of variance (ANOVA) was used to compare BW dimensions among groups.

Results: Mean BW dimensions in a healthy periodontium were recorded as $1.83 \pm 0.23 \mathrm{~mm}$. At sites with advanced periodontitis, this was $1.52 \pm 0.36 \mathrm{~mm}$ which was statistically significantly

different from the former $(\mathrm{p}<0.05)$ and at sites with residual $\mathrm{PD} \geq 5 \mathrm{~mm}$ but no BOP after phase

one therapy, mean BW was $1.85 \pm 0.25 \mathrm{~mm}$.

Conclusions: BW dimensions differ significantly in disease as compared to health but after phase one therapy the dimensions tend to be restored.
\end{abstract}

Keywords: Biologic width, Periodontal disease, Gingiva.

Key Messages: This article focuses on analyzing changes in biologic width dimensions in periodontal health and disease and also changes in dimensions observed after phase one therapy. A knowledge of these changes will prove valuable while planning periodontal treatment.

\section{Introduction}

Biologic width (BW), an important concept in periodontics and restorative dentistry, refers to the soft tissue attachment of periodontal tissues to the tooth surface coronal to the crest of the alveolar bone. It acts as a natural soft tissue seal around the tooth protecting the alveolar bone from infection and disease. ${ }^{1}$ There is a general consensus that placement of restorative margins within the biologic width frequently leads to gingival inflammation, clinical attachment loss, and bone loss. This is thought to be due to the destructive inflammatory response to microbial plaque located at deeply placed restorative margins. ${ }^{2,3,4}$ Understanding and clinically applying the concept of BW is key to maintaining periodontal health in the presence of dental restorations.

The dimensions and relationship of structures of the dentogingival attachment were first described by Gargiulo et $\mathrm{al}^{1}$ by studying human autopsy specimens. The average dimensions for sulcus depth, junctional epithelium and connective tissue attachment were mentioned as $0.69 \mathrm{~mm}$, $0.97 \mathrm{~mm}$ and $1.07 \mathrm{~mm}$ respectively. Based on this work, the term biologic width was coined by Cohen in 1962 and was described as those junctional epithelial and connective tissue elements of the dentogingival continuum that occupy the space between the base of the gingival crevice and the alveolar crest. ${ }^{5} \mathrm{BW}$ was thus calculated to be an average of $2.04 \mathrm{~mm}$. Since then, this 2 $\mathrm{mm}$ dimension has become the norm for use in all clinical situations. However, mean values may not always clearly predict any particular clinical situation as significant variations have been reported in $\mathrm{BW}$ dimensions from tooth to tooth and site to site even within the same individual. Moreover, a large range of values was observed in the Gargiulo study particularly for epithelial attachment $(1.0 \mathrm{~mm}-9.0 \mathrm{~mm})$. It has also been stated that BW measurements taken from tissues of a healthy periodontium should not be generalized for use in periodontal pathology. ${ }^{6}$

Novak et al, ${ }^{6}$ in a study, reported that the supracrestal connective tissue attachment is an inconstant component of the periodontal apparatus that may provide periodontal stability to teeth with bone loss as well as provide an unusually large BW. The mean distance between the most apical extent of subgingival calculus or plaque and the crest of the alveolar bone has been reported to remain constant with a value of $1.94 \mathrm{~mm}$ to $1.97 \mathrm{~mm} .{ }^{7}$ Literature contains scant information regarding BW dimensions in patients with chronic periodontitis. To the best of our knowledge, no clinical study has aimed to compare BW dimensions in health and disease. The present study was designed to clinically determine the BW dimensions in a healthy periodontium and to compare them with those in 
inflammatory periodontal disease before and after phase one therapy. It also aimed to evaluate the differences in the biologic width dimensions across different tooth types and different sites around a tooth both in health as well as disease.

\section{Material and Methods}

The study was conducted in Department of Periodontics, Post graduate institute of dental sciences, Rohtak. The study sample consisted of 41 systemically healthy patients with an age range of $18-42$ years. Out of these 21 patients had a healthy periodontium as depicted by plaque index $<1$, gingival index $<1$, probing depths $\leq$ $3 \mathrm{~mm}$, absence of any clinical attachment loss and having no history of periodontitis. Most of these patients were student volunteers. The other 20 patients included had advanced periodontitis with probeable pocket depths $\geq 6$ $\mathrm{mm}$ at $>30 \%$ of the sites and a generalized horizontal bone loss as revealed by the panoramic radiograph. Subjects were not included if they needed any antibiotic prophylaxis for treatment, taking any drug affecting the periodontium or were smokers. After recording of readings, patients with advanced periodontitis were instructed regarding oral hygiene maintenance and given four to six sessions of scaling and root planing. These were again recalled after 3 months for BW evaluation. Full mouth PI, GI, BOP and PD were recorded at all sites. Sites with residual probing depths $\geq 5 \mathrm{~mm}$ after phase one therapy and presenting with no bleeding on probing were evaluated for BW dimensions. A total of 1596 healthy sites, 1044 sites with advanced periodontitis and 516 sites with residual $\mathrm{PD} \geq 5 \mathrm{~mm}$ but no BOP after phase I therapy were evaluated. The study protocol was approved by institutional review board and was carried out in accordance with the ethical standards outlined in the 1964 declaration of Helsinki as revised in 2000. All patients were fully informed of the investigation and signed informed consent forms prior to examination.

Full mouth Plaque index (Silness \& Loe) ${ }^{8}$ and bleeding on probing (BOP) scores (absent $=0$, present $=1$ ) were recorded for each patient. Measurements were made with a standardized periodontal probe by one examiner at six sites along each tooth:-Mid-facial, Mid-lingual/palatal, Mesio-facial, Mesio-lingual/palatal, Disto-facial and Disto-lingual/palatal. The probe was fitted tightly with a silicon rubber sliding stop. The probe was held in a corono apical direction, firmly against the tooth so that the rubber stop would gently touch the incisal edge or the occlusal surface and the tip of the probe is at the free gingival margin. This distance (FGM) was measured. Next, the distance of the probe tip to the rubber stop was measured as the probe is inserted into the gingival sulcus (GS). Under local anesthesia, the probe was then advanced further apically till bone crest was felt. This distance (BC) was also recorded. All these distances were measured with a vernier caliper to the nearest $0.1 \mathrm{~mm}$. Sulcus depth (SD) was then calculated by subtracting distance FGM from GS and Biologic width (BW) by subtracting distance GS from BC.

All measurements were made by a single examiner. Each reading was taken twice and the average of the two measures was recorded to minimize error. Calibration exercises to achieve $\geq 90 \%$ intra-examiner reproducibility of measurements were conducted before the study started.

\section{Statistical analysis}

Statistical analysis was carried out by computer software (SPSS 17.0). Mean and standard deviation for the three groups were calculated and one way analysis of variance (ANOVA) was used to compare BW dimensions among groups.

\section{Results}

Mean BW dimensions in a healthy periodontium were recorded as $1.83 \pm 0.23 \mathrm{~mm}$. At sites with advanced periodontitis, this was $1.52 \pm 0.36 \mathrm{~mm}$ and at sites with residual $\mathrm{PD} \geq 5 \mathrm{~mm}$ but no BOP after phase one therapy mean $\mathrm{BW}$ was $1.85 \pm 0.25 \mathrm{~mm}$.

BW was found to increase as we go posteriorly along the arch with the maximum mean dimension as $1.96 \pm 0.25$ $\mathrm{mm}$ seen in molars (Table 1). Among the tooth sites, maximum mean dimensions were seen along the interdental sites as compared to mid-facial sites with a difference of nearly $0.5 \mathrm{~mm}$ in healthy sites (Table 2). In advanced periodontitis cases, this difference decreased to nearly $0.3 \mathrm{~mm}$. Measurement of biologic width after phase one therapy revealed no statistically significant difference from dimensions in health at all the sites (Table 3). BW dimensions in advanced periodontitis cases across different probing depths with and without bleeding on probing revealed no statistically significant difference (Table 4).

Table 1: Biologic width dimensions in health across different tooth sites

\begin{tabular}{|l|c|}
\hline \multicolumn{1}{|c|}{ Tooth site } & $\begin{array}{c}\text { Biologic width } \\
\text { mean } \pm \text { S.D } \text { (in mm) }\end{array}$ \\
\hline Mesial & $1.94 \pm$ O.19* \\
\hline Mid-facial/lingual & $1.59 \pm 0.13^{*}$ \\
\hline Distal & $1.96 \pm 0.16^{*}$ \\
\hline
\end{tabular}

$*=p<0.05$, statistically significant difference among the three groups

Table 2: Biologic width dimensions in health across different arch positions

\begin{tabular}{|l|c|}
\hline \multicolumn{1}{|c|}{ Arch Position } & $\begin{array}{c}\text { Biologic Width } \\
\text { mean } \pm \text { S.D (in mm) }\end{array}$ \\
\hline Anterior & $1.73 \pm 0.16^{*}$ \\
\hline Premolar & $1.87 \pm 0.24^{*}$ \\
\hline Molar & $1.96 \pm 0.25^{*}$ \\
\hline
\end{tabular}

$*=\mathrm{p}<0.05$, statistically significant difference among the three groups. 
Table 3: Biologic width dimensions across the three groups

\begin{tabular}{|l|c|c|c|}
\hline Tooth Surface & $\begin{array}{c}\text { Health } \\
\text { mean } \pm \text { S.D } \\
\text { (in mm) }\end{array}$ & $\begin{array}{c}\text { Advanced Periodontitis } \\
\text { \{without treatment } \\
\text { mean } \mathbf{\text { S.D }} \\
\text { (in mm) }\end{array}$ & $\begin{array}{c}\text { Advanced Periodontitis } \\
\text { \{after phase I therapy } \\
\text { mean } \pm \text { S.D } \\
\text { (in mm) }\end{array}$ \\
\hline Mesial & $1.94 \pm 0.19$ & $1.68 \pm 0.34^{*}$ & $1.88 \pm 0.24$ \\
\hline Mid-facial/lingual & $1.59 \pm 0.13$ & $1.40 \pm 0.27^{*}$ & $1.69 \pm 0.26$ \\
\hline Distal & $1.96 \pm 0.16$ & $1.77 \pm 0.36^{*}$ & $1.85 \pm 0.38$ \\
\hline
\end{tabular}

$*=\mathrm{p}<0.05$, statistically significant difference among the three groups.

Table 4: Biologic width dimensions in advanced periodontitis according to presence of bleeding on probing (BOP)

\begin{tabular}{|l|c|c|c|}
\hline $\begin{array}{c}\text { Bleeding on } \\
\text { probing (BOP) }\end{array}$ & $\begin{array}{c}\text { Probing depth= } \\
\mathbf{2 - 4} \mathbf{~ m m} \\
\text { mean } \pm \text { S.D(in mm) }\end{array}$ & $\begin{array}{c}\text { Probing depth= } \\
\text { 4-6 } \mathbf{~ m m} \\
\text { mean } \pm \text { S.D(in mm) }\end{array}$ & $\begin{array}{c}\text { Probing } \\
\text { depth } \geq \mathbf{6 m m} \\
\text { mean } \pm \text { S.D(in } \mathbf{~ m m})\end{array}$ \\
\hline BOP present & $1.62 \pm 0.34$ & $1.50 \pm 0.33$ & $1.48 \pm 0.39$ \\
\hline BOP absent & $1.72 \pm 0.32$ & $1.68 \pm 0.36$ & $1.74 \pm 0.39$ \\
\hline
\end{tabular}

\section{Discussion}

The present study evaluated the differences in BW dimensions in periodontal health and disease. Literature lacks sufficient evidence regarding BW dimensions in periodontal disease. Only one study ${ }^{6}$ tried to examine the changes in BW that might occur in periodontitis subjects with severe, generalized, chronic periodontitis. It was found that the average $\mathrm{BW}$ was $3.95 \pm 1.04 \mathrm{~mm}$.

It has previously been demonstrated that considerable variability exists in the histologic BW in periodontal health and mild periodontitis ${ }^{1}$ but no measurements of BW in more advanced cases of periodontitis and those established after treatment are available.

In the present study, BW dimensions in health were found to be almost similar to those found by Vacek et $\mathrm{al}^{9}$ who also stated that individual variations do exist in $\mathrm{BW}$ dimensions, a statement supported by other recent studies as well. ${ }^{10}$ It was seen that BW does decrease significantly in cases with advanced periodontitis with a PPD of $\geq 6 \mathrm{~mm}$ as compared to those in health. These dimensions were then restored to those seen in health after phase one therapy. The results differ from another study $^{6}$ in severe chronic periodontitis cases which reported BW dimensions to be almost twice to those seen in the present study. This could be because of the assessment of dimensions of interproximal areas only in that study. Another reason could be the difference in the methods of measurement. While the previous study relied on subtraction of clinical attachment level from the radiographic bone crest level, the present study chose both clinical measurements. The authors also found that the shallowest pockets had greater BW dimensions. The mean BW dimensions in pockets with PPD of $\geq 6 \mathrm{~mm}$ in the present study was $1.52 \pm 0.36 \mathrm{~mm}$ while those obtained in the aforementioned study were almost double, that is, $3.33 \pm 1.17 \mathrm{~mm}$. Another analysis that was done in the present study was the comparison of dimensions at sites with and without bleeding on probing. Areas with bleeding on probing, a marker of disease activity, had lesser BW dimensions as compared to those without active disease.

Only sites with advanced periodontitis were taken in the present study. After having undergone phase one therapy, sites with residual PPD of $\geq 5 \mathrm{~mm}$, that is, those requiring periodontal surgery were also evaluated. It has been seen that following non-surgical therapy, epithelial attachment tends to reestablish. ${ }^{11}$ This is clearly illustrated by the BW dimensions established after the phase one therapy.

In the previous landmark histologic study ${ }^{1}$ it was seen that connective tissue attachment is the most consistent element of the BW and most variability is seen in the epithelial attachment which was seen to be 0.74 $\mathrm{mm}$ and $0.71 \mathrm{~mm}$ in phase three and four of passive eruption respectively. It is difficult to compare results of a clinical study with a study depending on histologic or radiographic methods of $\mathrm{BW}$ measurement.

Various methods have been used to measure BW. Among these, trans sulcular probing has earlier been proven to be a reliable method to clinically assess alveolar crest levels. ${ }^{12-15} \mathrm{BW}$ can be easily determined clinically by this relatively simpler method along different teeth and surfaces. Radiographic method on the other hand can only be used for proximal sites.

Determination of BW is important in health for clinical procedures like crown lengthening for restorative purpose. It is also important to see whether any change in dimensions of BW occurs during periodontal disease because the epithelial and connective tissue attachment serve as a barrier to further disease progression. In the present study, while the BW is found to statistically significantly decrease in disease, it is also seen that these dimensions are restored to those in health after scaling and root planing. 


\section{Conclusion}

BW dimensions differ significantly in disease as compared to health but after phase one therapy the dimensions tend to be restored. Before beginning any restorative procedure, it is important to first restore periodontal health and then proceed with the restoration/prosthesis.

Funding: No funding sources.

Conflict of interest: None declared.

\section{References}

1. Gargiulo AW, Wentz FM, Orban B. Dimensions and relations of the dento-gingival junction in humans. $J$ Periodontol 1961;32:261-267.

2. Ingber JS, Rose LF, Coslet JG. The "biologic" width A concept in periodontics and restorative dentistry. Alpha Omegan 1977;70:62-65.

3. Kois JC (1994). Altering gingival levels: The restorative connection. Part I: Biologic variables. J Esthet Dent 1994;6:3-9. 17.

4. Smukler H, Chaibi M. Periodontal and dental considerations in clinical crown extension: A rational basis for treatment. Int J Periodontics Restorative Dent 1997; 17:464-77.

5. Cohen DW (1999). Periodontal preparation of the mouth or restorative dentistry. Presented at the Walter Reed Army Medical Center, Washington, DC. Armitage GC. Development of a classification system for periodontal diseases and conditions. Ann Periodontol 1962;4:1-6.

6. Novak MJ, Albather HM, Close JM (2008). Redefining the Biologic Width in Severe, Generalized, Chronic Periodontitis: Implications for Therapy. J Periodontol 2008;79:1864-69.

7. Waerhaug J. The gingival pocket. Odontol Tidskr 1952;60:95-134.
8. Silness J, Loe H (1964). Periodontal disease in pregnancy. II. Correlation between oral hygiene and periodontal condition. Acta Odont Scand 1964;22:12135.

9. Vacek JS, Gehr ME, Asad DA, Richardson AC, Giambarresi LI. The dimensions of the human dentogingival junction. Int $J$ Periodontics Restorative Dent 1994;14:154-65.

10. Arora R, Narula SC, Sharma RK, Tewari S. Supracrestal Gingival Tissue: Assessing Relation with Periodontal Biotypes in a Healthy Periodontium. Int J Periodontics Restorative Dent 2013;33:763-771.

11. Lindhe J, Westfelt E, Nyman S, Socransky SS, Heijl L, Bratthall G. Healing following surgical/non-surgical treatment of periodontal disease. A clinical study. J Clin Periodontol 1982;9:115-128.

12. Arora R, Narula SC, Sharma RK, Tewari S. Evaluation of Supracrestal Gingival Tissue After Surgical Crown Lengthening: A 6-Month Clinical Study. J Periodontol. 2013;84:934-40.

13. Greenberg J, Laster L, Listgarten MA (1976). Transgingival probing as a potential estimator of alveolar bone level. J Periodontol 1976;47:514-17.

14. Ursell MJ (1989). Relationship between alveolar bone levels measured at surgery, estimated by transgingival probing and clinical attachment level measurements. $J$ Clin Periodontol 1989;16:81-6.

15. Lindhe J, Westfelt E, Nyman S, Socransky SS, Haffajee AD (1984). Long-term effect of surgical/non-surgical treatment of periodontal disease. J Clin Periodontol 1984;11:448-58.

How to cite the article: Arora R., Sharma R., Tewari S., Narula S., Kapoor H. From health to disease- How consistent is the biologic width? IP Int J Periodontol Implantol 2018;3(3):111-114. 